\title{
Left ventricular decompression through a patent foramen ovale in a patient with hypertrophic cardiomyopathy: a case report Giuseppe Ando'*1, Fabrizio Tomai ${ }^{1}$ and Pier A Gioffre'2
}

\author{
Address: ${ }^{1}$ Department of Cardiac Surgery, University of Rome Tor Vergata, Rome, Italy and ${ }^{2}$ European Hospital, Rome, Italy \\ Email: Giuseppe Ando'* - giuseppe.ando@tiscali.it; Fabrizio Tomai - f.tomai@tiscali.it; Pier A Gioffre' - f.tomai@tiscali.it \\ * Corresponding author
}

This article is available from: http://www.cardiovascularultrasound.com/content/2/I/2

(C) 2004 Ando' et al; licensee BioMed Central Ltd. This is an Open Access article: verbatim copying and redistribution of this article are permitted in all media for any purpose, provided this notice is preserved along with the article's original URL.

\begin{abstract}
The foramen ovale is considered an unidirectional flap-like valvular structure. Yet, it may increase in size and allow a continuous left-to-right shunt in order to reduce left ventricular filling pressures.

We report the case of a 63-year-old woman with hypertrophic cardiomyopathy, referred for percutaneous closure of a coexisting secundum atrial septal defect. Before catheterization, however, transesophageal echocardiography revealed a continuous left-to-right shunt within the atrial septum, thus suggesting the diagnosis of patent foramen ovale with stable left-to-right shunt. At catheterization, performed under general anesthesia and transesophageal echocardiographic monitoring, left ventricular early- and end-diastolic pressures were 2 and $12 \mathrm{mmHg}$ and pulmonaryto-systemic flow ratio was I.4. Provocative maneuvers were not able to reverse the shunt. In order to assess the effect of the increased left ventricular preload due to the abolition of the shunt, an Amplatzer sizing balloon was inflated for 5 minutes across the patent foramen ovale. Diastolic pressures rose up to 5 and $18 \mathrm{mmHg}$, respectively. Such a worsening of left ventricular function suggested us not to perform the closure procedure.

Transcatheter closure of any interatrial communication with stable left-to-right shunt induces an abrupt overload of the left ventricle that may cause acute heart failure in patients with coexisting left ventricular dysfunction. The hemodynamic evaluation of left ventricular function during transient abolition of the shunt is an useful tool in order to establish the most correct therapeutic strategy. The closure procedure should not be performed if a worsening of left ventricular function occurs.
\end{abstract}

\section{Background}

Transcatheter percutaneous closure of ASD is recommended as a preferable alternative to surgical repair, since excellent results in terms of efficacy and complications [1] are associated with shorter hospitalization and lower morbidity [2]. It should be kept in mind, yet, that the sudden interruption of the left-to-right shunt at the time of the definitive percutaneous closure causes an abrupt LV overload and a consequent increase in myocardial oxygen consumption. Such hemodynamic changes may be harmful in patients with LV dysfunction [3] and in elderly patients [4] with reduced LV compliance and can lead to acute heart failure [3-6]. Thus, whenever an ASD coexists with LV dysfunction, a rapid evaluation of the hemodynamic effects of the abolition of the left-to-right shunt is useful for clinical decision making. 
We report the case of an apparent secundum ASD in whom both TEE and a real-time hemodynamic evaluation of LV function during transient abolition of the shunt helped us to advance the most accurate diagnosis and to establish the most correct therapeutic strategy.

\section{Case presentation}

A 63-year-old woman with apical hypertrophic cardiomyopathy, complaining of moderate effort dyspnea and with no history of cerebrovascular accidents, was referred to our Department for hemodynamic characterization and possible percutaneous closure of a secundum ASD. Before catheterization, however, multiplane color Doppler TEE revealed a turbulent, continuous left-to-right shunt within a double contour image of the atrial septum (Figure 1), that is the hallmark of PFO. Moreover, the presence of 16mm wall thickness localized at the mid-distal interventricular septum confirmed the presence of an apical hypertrophic cardiomyopathy. At cardiac catheterization, performed under general anesthesia and TEE monitoring, pulmonary-to-systemic flow ratio was 1.4 , without pulmonary arterial hypertension and with normal pulmonary resistance. Provocative maneuvers during contrast injections into the right femoral vein were not able to reverse the shunt. Coronary arteries were normal and LV angiography confirmed apical hypertrophy (Figure 2 and Video 1-See additional file 1). LV early- and end-diastolic pressures were 2 and $12 \mathrm{mmHg}$, respectively. The atrial septum was then crossed with a multipurpose diagnostic catheter: a pressure gradient was present between left (10 $\mathrm{mmHg}$ ) and right $(4 \mathrm{mmHg})$ atrium and, at TEE, the color jet appeared widened. Pulmonary venous angiography (Figure 3 and Video 2-See additional file 2) confirmed the left-to-right shunt through the abnormal interatrial communication.

Before proceeding to PFO closure, we performed a hemodynamic evaluation aimed at assessing the effect of the increased LV preload due to the abolition of the left-toright shunt. For this purpose, an exchange stiff guide wire was kept in the left upper pulmonary vein and an Amplatzer (AGA Medical Corporation, Golden Valley, $\mathrm{MN}$, USA) sizing balloon was introduced over the wire across the PFO and inflated to abolish the shunt [7]. LV early- and end-diastolic pressures, 5 minutes after SB inflation, rose up to 5 and $18 \mathrm{mmHg}$, respectively (Figure 4). Such a worsening of LV diastolic function due to the PFO occlusion suggested us not to perform the definitive procedure with the Amplatzer occluder.

The wide application of contrast TEE has revealed that paradoxical embolism through a PFO is likely to represent an under-recognized cause of stroke [8], but fewer reports have highlighted the possibility of a stable left-to-right shunt through a PFO [9], since the foramen ovale is gen- erally considered an unidirectional flap-like valvular structure, that is functionally closed when left atrial pressure is higher than right. Nevertheless, it has been speculated that the foramen ovale may increase in size and allow a left-to-right overflow secondary to pressureinduced left atrial enlargement [5]; such a shunt may be easily misdiagnosed as secundum ASD at transthoracic echocardiography. Moreover, in the case of LV restrictive physiology, like in hypertrophic cardiomyopathy, a continuous left-to-right shunt through a PFO may act as an unloading mechanism for the left atrial chamber finalized at reducing LV filling pressures. Therefore it may be useful, in such cases and prior to any interventional procedure, to perform, under the controlled conditions due to general anesthesia, a rapid hemodynamic evaluation of the effect of the transient abolition of the shunt on LV function. This evaluation can easily be obtained with the inflation of the sizing balloon across the interatrial communication. The percutaneous closure procedure should not be performed if a worsening of LV function occurs.

\section{Conclusions}

The abrupt LV overload due to transcatheter closure of ASD may induce acute heart failure in patients with associated LV dysfunction. The assessment of LV filling pressures during transient abolition of the shunt permits a real time evaluation of LV function in the new hemodynamic conditions that is useful to clinicians in order to manage the patient with the most appropriate therapeutic strategy. Such evaluation should be performed, prior to definitive closure of any abnormal interatrial communication with a stable left-to-right shunt, in all patients with coexisting LV dysfunction in whom the consequent increase in LV preload could not be hemodynamically tolerated and lead to acute heart failure.

\section{List of abbreviations}

ASD Atrial Septal Defect

\section{Left Ventricular}

PFO Patent Foramen Ovale

TEE Transesophageal Echocardiography

\section{Competing interests}

None declared.

\section{Authors' contributions}

GA performed the echocardiographic evaluation and FT carried out all the catheterization procedure. FT and PAG conceived the study and coordinated the clinical management of the patient. GA prepared and edited and FT reviewed the manuscript. All authors read and approved the final manuscript. 


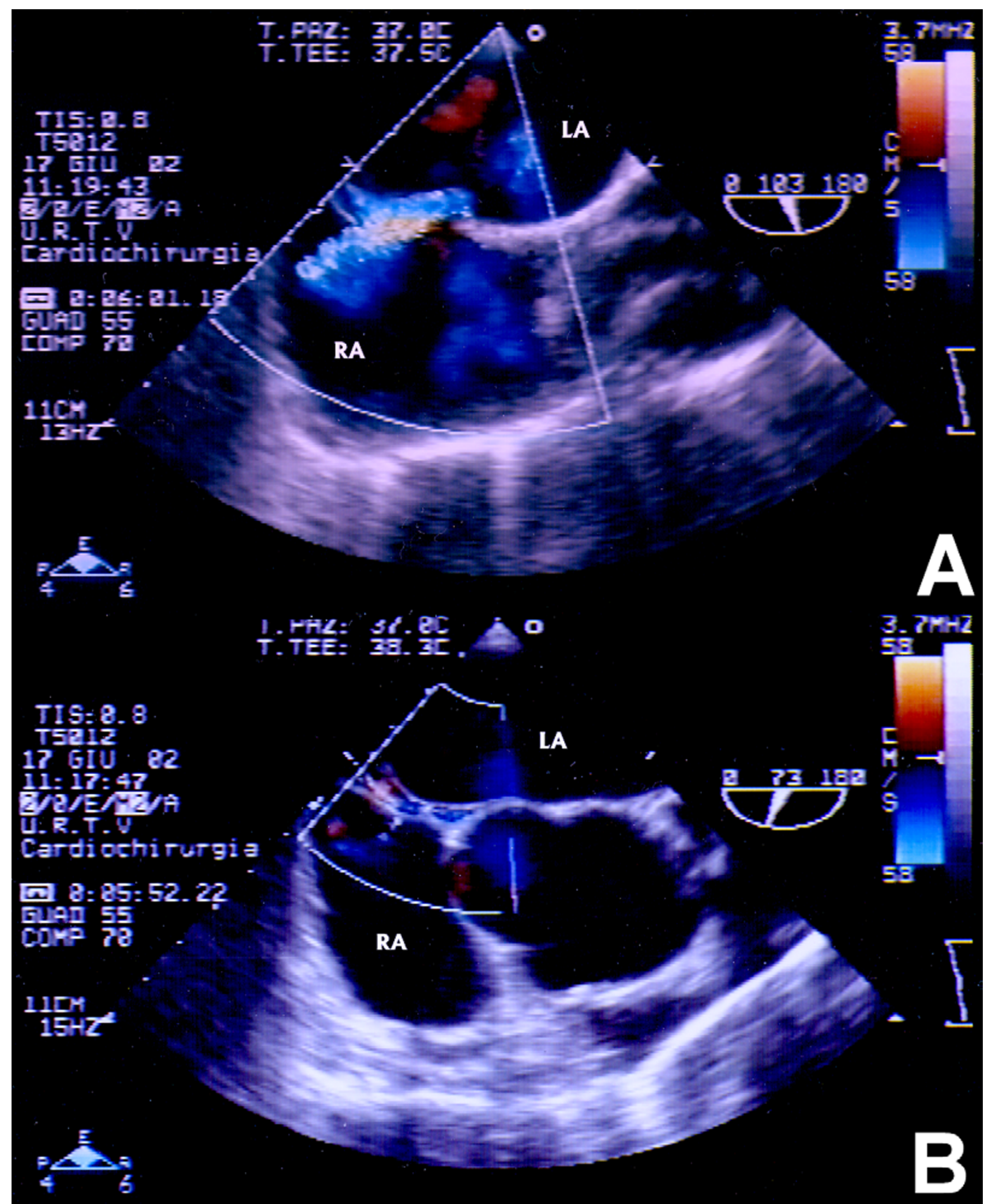

Figure I

Multiplane color Doppler TEE. The diagnosis of PFO was advanced with multiplane TEE demonstration of a turbulent, continuous left-to-right shunt $(A)$ within a double contour of the atrial septum (B). LA, left atrium; RA, right atrium. 


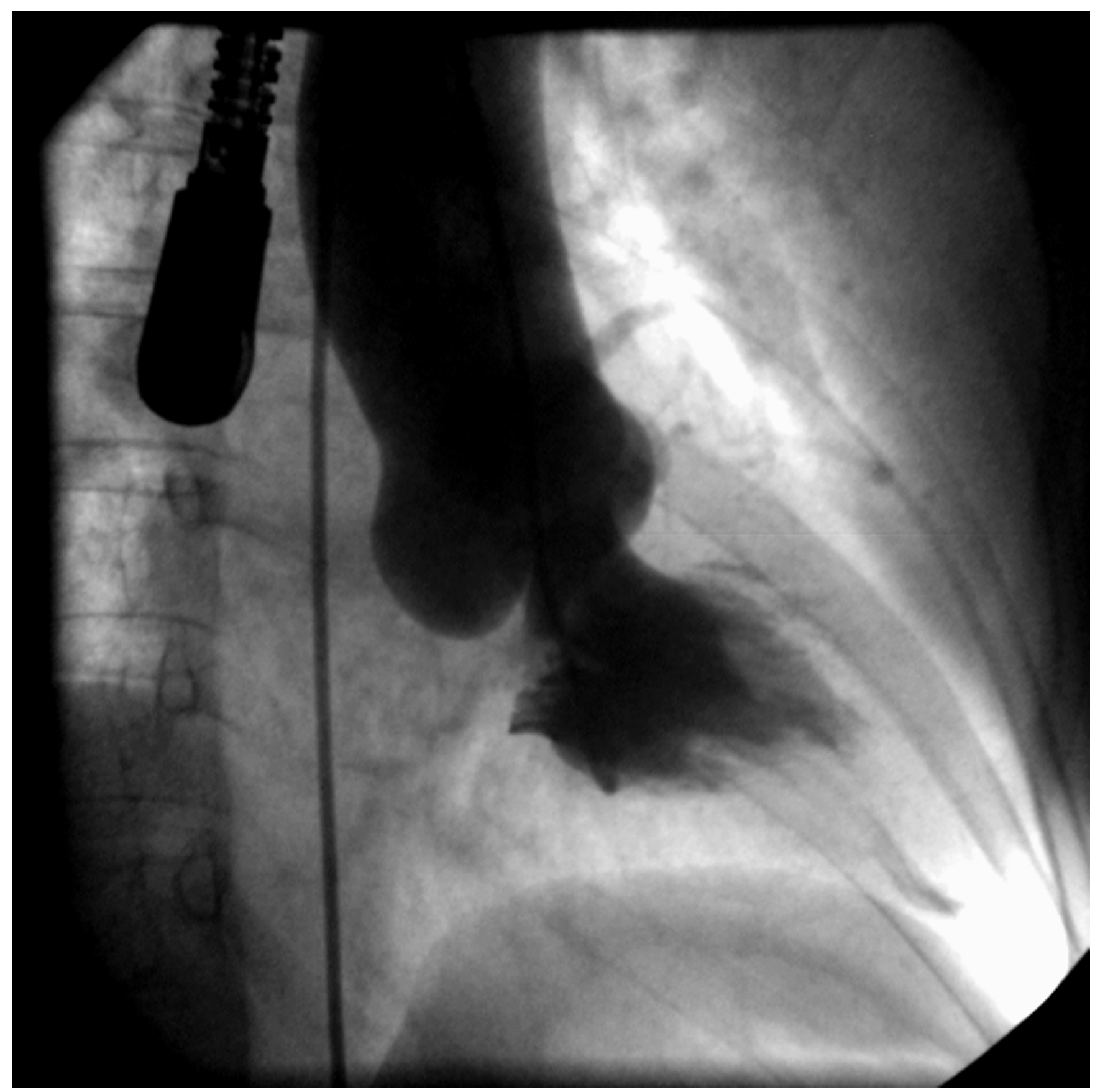

\section{Figure 2}

End-systolic left ventricular angiogram Left ventricular angiography showed apical hypertrophy with low end-systolic volume and hourglass shape of the ventricular chamber. 


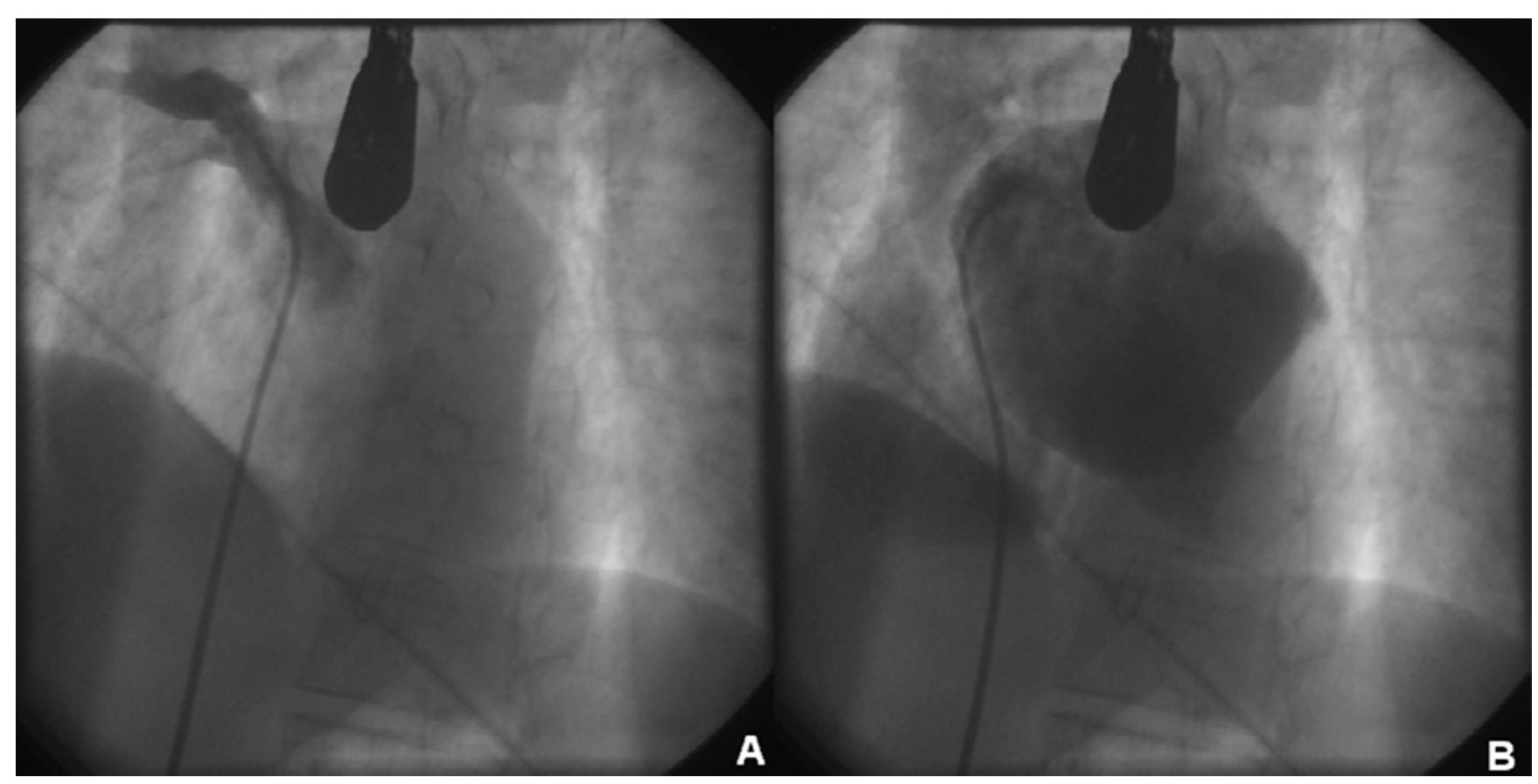

\section{Figure 3}

Right upper pulmonary venous angiography. The injection in the right upper pulmonary vein (A) revealed passage of contrast media from an enlarged left atrium to the right atrium (B) through the abnormal interatrial communication. 

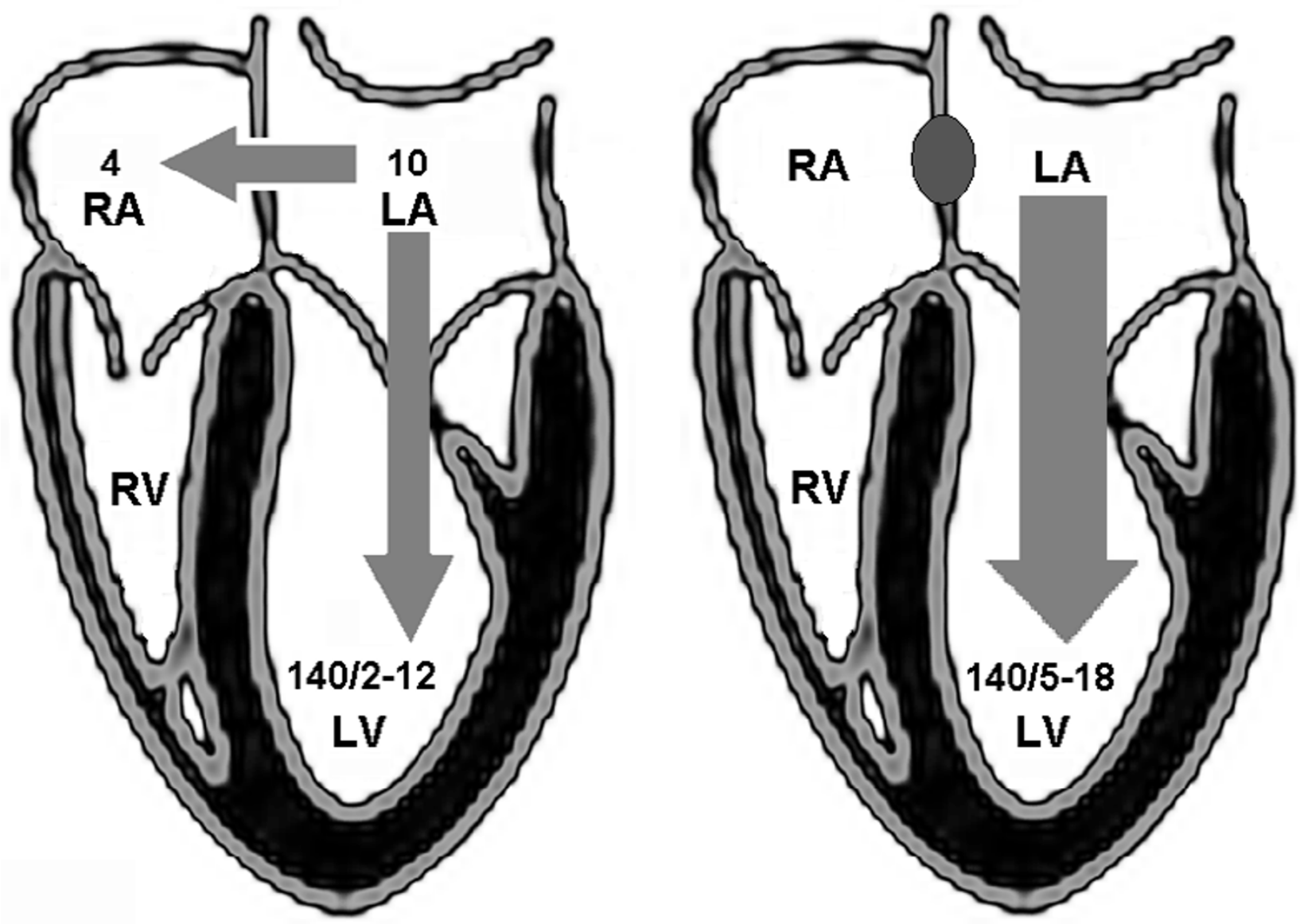

Figure 4

Schematic representation of flows and pressures. Flows and pressures $(\mathrm{mmHg})$ in the four heart chambers before (left) and 5 minutes after (right) SB inflation.

\section{Additional material}

\section{Additional File 1}

Left ventricular angiography. Left ventricular angiography showed apical hypertrophy with low end-systolic volume and hourglass shape of the ventricular chamber.

Click here for file

[http://www.biomedcentral.com/content/supplementary/14767120-2-2-S1.mov]

\section{Additional File 2}

Right upper pulmonary venous angiography. The injection in the right upper pulmonary vein reveals passage of contrast media from an enlarged left atrium to the right atrium through the abnormal interatrial communication.

Click here for file

[http://www.biomedcentral.com/content/supplementary/14767120-2-2-S2.mov]

\section{Acknowledgements}

GA has received a grant by the Italian Society of Cardiology for a Fellowship in Interventional Cardiology at the Department of Cardiac Surgery of the Tor Vergata University of Rome.

Written consent was obtained from the patient for the publication of this case report.

\section{References}

I. Berger F, Ewert P, Bjornstad PG, Dahnert I, Krings G, Brilla-Austenat I, Vogel M, Lange PE: Transcatheter closure as standard treatment for most interatrial defects: experience in 200 patients treated with the Amplatzer Septal Occluder. Cardiol Young 1999, 9:468-473.

2. Berger F, Vogel M, Alexi-Meskishvili V, Lange PE: Comparison of results and complications of surgical and Amplatzer device closure of atrial septal defects. J Thorac Cardiovasc Surg 1999, I I 8:674-680.

3. Tomai F, Gaspardone A, Papa M, Polisca P: Acute left ventricular failure after transcatheter closure of a secundum atrial septal defect in a patient with coronary artery disease: a critical reappraisal. Catheter Cardiovasc Interv 2002, 55:97-99. 
4. Ewert P, Berger F, Nagdyman N, Kretschmar O, Lange PE: Acute left heart failure after interventional occlusion of an atrial septal defect. $Z$ Kardiol 200I, 90:362-366.

5. Ewert P, Berger F, Nagdyman N, Kretschmar O, Dittrich S, AbdulKhaliq $\mathrm{H}$, Lange PE: Masked left ventricular restriction in elderly patients with atrial septal defects: a contraindication for closure? Catheter Cardiovasc Interv 200I, 52: I77-I80.

6. Bialkowski J, Kusa J, Szkutnik M, Kalarus Z, Banaszak P, BermudezCanete R, Fernandez Pineda L, Zembala M: Percutaneous catheter closure of atrial septal defect. Short-term and mid-term results. Rev Esp Cardiol 2003, 56:383-388.

7. Gu X, Han YM, Berry J, Urness M, Amplatz K: A new technique for sizing of atrial septal defects. Catheter Cardiovasc Interv 1999, 46:5I-57.

8. Meier B, Lock JE: Contemporary management of patent foramen ovale. Circulation 2003, 107:5-9.

9. Schneider B, Zienkiewicz T, Jansen V, Hofmann T, Noltenius H, Meinertz T: Diagnosis of patent foramen ovale by transesophageal echocardiography and correlation with autopsy findings. Am J Cardiol 1996, 77:1202-1209.

Publish with Bio Med Central and every scientist can read your work free of charge

"BioMed Central will be the most significant development for disseminating the results of biomedical research in our lifetime. "

Sir Paul Nurse, Cancer Research UK

Your research papers will be:

- available free of charge to the entire biomedical community

- peer reviewed and published immediately upon acceptance

- cited in PubMed and archived on PubMed Central

- yours - you keep the copyright

Submit your manuscript here:

http://www.biomedcentral.com/info/publishing_adv.asp 